\title{
Mechanism of Rock Burst Revealed by Numerical Simulation and Energy Calculation
}

\author{
Wenlong Zhang (D, Nianjie Ma, Ji Ma, Chen Li, and Jianju Ren \\ School of Energy and Mining Engineering, China University of Mining and Technology (Beijing), Beijing 10083, China \\ Correspondence should be addressed to Wenlong Zhang; wenlong0523@163.com
}

Received 10 August 2020; Revised 26 September 2020; Accepted 14 October 2020; Published 2 November 2020

Academic Editor: Bangyou Jiang

Copyright (c) 2020 Wenlong Zhang et al. This is an open access article distributed under the Creative Commons Attribution License, which permits unrestricted use, distribution, and reproduction in any medium, provided the original work is properly cited.

\begin{abstract}
We propose a new computational method to calculate the storage elastic energy value of surrounding rocks based on numerical simulation and theoretical calculation. By calculating the difference value in energy under different force states and comparing them with the energy level when rock burst occurs, we get the mechanism of rock burst: when roadway and surrounding rocks are in the condition of large ratio bias force field, certain triggering stress causes mass release of the elastic energy of surrounding rocks around the roadway, and when the energy reaches a certain level, rock burst will occur. We also put forward the specific force field conditions and triggering stress values of rock burst, which is of great guiding significance for the mechanism disclosure, monitoring, and control of rock burst.
\end{abstract}

\section{Introduction}

At present, rock burst is a common dynamic disaster in underground coal mines, deep buried tunnels, and underground metal mines [1-3], mainly because its mechanism is not clear enough [4], which leads to unclear monitoring and early warning methods. In the past research, the mechanism of rock burst mainly includes strength theory [5], energy theory [6], stiffness theory [7], rock burst tendency theory [8], "three factors" theory [9], instability theory [10], "three criteria" theory [11], butterfly impact mechanism [12, 13], dynamic and static combined load principle [14, 15], and rock burst start-up theory [16]. These theories reveal the occurrence mechanism of rock burst from various perspectives, but they either have their limitations or used too complex model and do not have better guidance for the monitoring and control of rock burst on-site. The famous "Ockham razor" principle [17] believes that the simplest explanation of the phenomenon is often more correct than the complex one. So, a feasible numerical model should be adopted for quantitative calculation to explain the occurrence mechanism of rock features [18]. And meanwhile, the real mechanism should be able to explain the occurrence principle of rock burst in various situations, rather than only explaining special cases.

The failure of coal and rock mass is a change in state driven by energy [19]. Therefore, studying the deformation and failure process of coal and rock mass from the perspective of energy will truly reflect its failure law [20]. According to the energy theory, when the energy given to the surrounding rock system by the outside exceeds the energy consumed before its failure, the rock burst will occur, and there is no doubt that this is correct, but there is no theoretical answer to how much energy will be released under what kind of mechanical state of system and triggering stress $(\Delta \mathrm{P})[21]$. Here, the $\Delta \mathrm{P}$ is often caused by roof breaking or leading abutment pressure [22-24].

The main monitoring methods of rock burst are microseismic (MS) monitoring [25-27], electromagnetic radiation [27], method of drilling bits [28], and stress monitoring [29]. Among these monitoring methods, MS monitoring is more representative and valuable, mainly due to its intuitiveness and application of vibration signal (MS event) monitoring. The main control measures are largediameter borehole pressure relief [30, 31], blasting pressure relief [2,32], roadway support [33], and hydraulic fracturing 
[34], but the monitoring and control methods are heavily dependent on the mechanism; otherwise, the monitoring and control measures are not based at all, for example, what energy level of MS events can reach the level of giving an early warning of the rock burst, whether the large-diameter pressure relief measure really play a role, and how to play a role.

In view of the above facts, this paper takes numerical simulation and theoretical calculation as means and calculates the release energy of system under different mechanical force states and $\Delta P$ based on the simplest model. The calculation method and the revealed mechanism of rock burst are obviously of great significance for the prevention and control of rock burst.

\section{Method}

The surrounding rocks of underground roadway or tunnel are in the state of three-dimensional stress, in order to simulate its surroundings more truly, and we take a certain range of bounded area and named it $\Omega$ (respect surrounding rock), set one hole (respect roadway or tunnel) in the center, and then apply an external force $(P 1, P 2, P 3)$ to the $\Omega$ area, where $\mathrm{P}_{1}, \mathrm{P}_{2}$, and $\mathrm{P}_{3}$ are the maximum force, intermediate force, and minimum force applied to $\Omega$, respectively. Under the external force, unit in the area will be subjected to the stress of $\left(\sigma_{1 \mathrm{i}}, \sigma_{2 \mathrm{i}}, \sigma_{3 \mathrm{i}}\right)$, where $\sigma_{1 i}, \sigma_{2 i}$, and $\sigma_{3 i}$ are the maximum principal stress, intermediate principal stress, and minimum principal stress of unit, respectively. So the elastic energy of unit $(f(x, y, z))$ is as follows [35]:

$$
\begin{aligned}
f(x, y, z)= & \frac{1}{2 E_{i}}\left[\sigma_{1 i}^{2}+\sigma_{2 i}^{2}+\sigma_{3 i}^{2}-2 \mu_{i}\right. \\
& \left.\cdot\left(\sigma_{1 i} \sigma_{2 i}+\sigma_{2 i} \sigma_{3 i}+\sigma_{1 i} \sigma_{3 i}\right)\right] * \Delta V_{i},
\end{aligned}
$$

where $E_{i}$ is the elastic modulus of unit and $\mu_{i}$ is Poisson's ratio of unit.

For the sake of expression, we define $(P 1, P 2, P 3)$ as the front state force (FSF). Under FSF, there is no plastic zone in the $\Omega$ region if it is an elastic model, the storage elastic energy of $\Omega$ (named $U_{\mathrm{FSF}}$ ) can be expressed by Equation (2), while if it is an elastoplastic model, there will be some plastic units $\left(\Omega_{p}\right)$ exit in $\Omega$, and others are elastic units $\left(\Omega_{s}\right)$; the stored elastic energy of $\Omega$ (named $U_{\mathrm{FSF}}^{\prime}$ ) is shown in Equation (3). The difference value (D-value) of elastic energy under FSF $\left(D_{\mathrm{FSF}}\right)$ should be expressed as Equation (4). Obviously, the D-value is the reduced energy of the system between elastic model and elastoplastic model under the FSF:

$$
\begin{aligned}
& U_{\mathrm{FSF}}=\iiint_{\Omega\left(\mathrm{P}_{1}, \mathrm{P}_{2}, \mathrm{P}_{3}\right)} f(x, y, z) \mathrm{d} V, \\
& U_{\mathrm{FSF}}^{\prime}=\iiint_{\Omega_{e}\left(P_{1}, P_{2}, P_{3}\right)} f(x, y, z) \mathrm{d} V e+\iiint_{\Omega_{p}\left(\mathrm{P}_{1}, \mathrm{P}_{2}, \mathrm{P}_{3}\right)} f(x, y, z) \mathrm{d} V p, \\
& D_{\mathrm{FSF}}=U_{\mathrm{FSF}}-U_{\mathrm{FSF} .}^{\prime}
\end{aligned}
$$

Under the influence of $\Delta P$, it is assumed that FSF changes to $(P 1+\Delta P, P 2, P 3)$; that is, the $\Delta P$ only increases to $P_{1}$. For the sake of expression, we define $(P 1+\Delta P, P 2, P 3)$ as the latter state force (LSF). So, under LSF, there is no plastic zone in $\Omega$ if it is an elastic model, the storage elastic energy of $\Omega$ (named $U_{\text {LSF }}$ ) can be expressed by Equation (5), while if it is an elastoplastic model, there will be some new plastic units $\left(\Delta \Omega_{\mathrm{p}}\right)$ arising in $\Omega$, and the total plastic units should be $\left(\Omega_{\mathrm{p}}+\Delta \Omega_{\mathrm{p}}\right)$; elastic units should be $\left(\Omega_{e}-\Delta \Omega_{p}\right)$, so the storage elastic energy of $\Omega$ (named $U_{\mathrm{FSF}}^{\prime}$ ) is shown in Equation (6). The D-value of elastic energy $\left(D_{\text {LSF }}\right)$ under LSF should be expressed as Equation (7). The D-value is the reduced energy of the system between elastic model and elastoplastic model under the LSF:

$$
\begin{aligned}
& U_{\mathrm{LSF}}=\iiint_{\Omega\left(P_{1}+\Delta P, P_{2}, P_{3}\right)} f(x, y, z) \mathrm{d} V \\
& U_{\mathrm{LSF}}^{\prime}=\iiint_{\left(\Omega_{e}-\Delta \Omega P\right)}\left(P_{1}+\Delta P, P_{2}, P_{3}\right) \\
& D_{\mathrm{LSF}}=U_{\mathrm{LSF}}-U_{\mathrm{LSF}}^{\prime}
\end{aligned}
$$

When rock burst occurs, the energy that causes huge damage to roadway and surrounding rock mass is mainly elastic wave energy [36]. In our method, all the released elastic energies will be converted into various forms of energy, such as dissipation energy, kinetic energy, and friction heat energy, only a part of which will convert into 
elastic wave energy, so we assume an energy conversion factor $(\beta)$ of elastic wave. According to relevant research $[37,38]$, the factor is generally between $1 \%$ and $10 \%$. So, the release elastic wave energy $(W)$ from FSF to LSF should have the difference value between the two $\mathrm{D}$ values and multiplied by $\beta$, as follows:

$$
W=\beta\left(D_{\mathrm{LSF}}-D_{\mathrm{FSF}}\right),
$$

where $\beta$ is the energy conversion factor of elastic wave energy.

The resulting calculation method is shown in Figure 1; the release energy caused by the change in mechanical state is finally obtained by four models. The three-dimensional stress of the unit mentioned in the above calculation method is very difficult to get in the theoretical calculation and field measurement, while FLAC $^{3 \mathrm{D}}$ just can simulate and get the stress state of each unit in the system, so as to calculate the elastic energy of the unit. According to the above calculation method, we set up a calculation system, the length and width of the system are $200 \mathrm{~m}$, the thickness is $1 \mathrm{~m}$, and a hole with the diameter of $5.6 \mathrm{~m}$ is set in the center of the system, as shown in Figure 2. The system uses the same kind of coal as medium, its cohesion (C) is $3 \mathrm{MPa}$, and its internal friction angle $(\psi)$ is $25^{\circ}$. The loading directions of $P_{1}, P_{2}$, and $P_{3}$ are up and down, front and back, and left and right, respectively. In order to simplify the calculation, we only change the size of $P_{1}$ to obtain the energy of the system when we simulate different force states. The initial force apply to the model is set to $P_{1}=P_{2}=P_{3}=20 \mathrm{MPa}$, and then, only the value of $P_{1}$ increases $1 \mathrm{MPa}$ each time until the system is fully plastic. When we calculate the energy under elastic model and elastoplastic model, we use the command of "model mech elastic" and "model Mohr" in the FLAC ${ }^{3 \mathrm{D}}$ program, respectively. In this way, we can get the storage elastic energy under different force states, so as to calculate the release energy of the system.

\section{Results}

After dozens of numerical simulations, we found that the farthest range of plastic zone reaches the model boundary when $P_{1}=58.7 \mathrm{MPa}$ under the elastoplastic model. We got the failure state of the elastic model and the elastoplastic model under each force state and discover that, under the elastic model, the system has not been damaged at all, but under the elastoplastic model, the stress concentration around the hole is obvious, the shape of the plastic area has experienced "circle," "ellipse," and "butterfly" successively, as shown in Figure 3. Finally, when the "butterfly leaf" extends to the boundary of the system, the system is completely plastic. The force state of the beginning of butterfly shape is $P_{1}=40 \mathrm{MPa}$ (the ratio of $P_{1} / P_{3}$ is 2 ), the butterfly state is particularly obvious when $P_{1}=50 \mathrm{MPa}$ (the ratio of $P_{1} / P_{3}$ is 2.5 ), the system is damaged in a large range when $P_{1}=58.6 \mathrm{MPa}$ (the ratio of $P_{1} / P_{3}$ is 2.93 ), and the system is all plastic when $P_{1}=58.7 \mathrm{MPa}$ (the ratio of $P_{1} / P_{3}$ is 2.935).
We calculate the elastic energy density of each unit, place them in the system according to the coordinates, and form the cloud chart to check the energy distribution; the cloud chart of a typical force state corresponding to Figure 3 is shown in Figure 4. With the increase in $P_{1}$, the storage elastic energy of the system under elastic model and elastoplastic model is all increasing. When $P_{1}$ is small, the difference in energy distribution between the two models is small, but with the increase in $P_{1}$, the energy change range of the elastoplastic model is larger than that of the elastic model, and the distribution of concentrated energy coincides with the position of butterfly leaf, indicating that there is a certain correlation between the distribution of energy and the distribution of plastic zone.

Table 1 lists the calculation energy results of the two models under different force states, and we can find that, with the increase in $P_{1}$, the storage elastic energy of the system increases from $10^{9} \mathrm{~J}$ to $10^{11} \mathrm{~J}$. The storage elastic energy of the elastic model in each mechanical state is always greater than that of the elastoplastic model, and according to Method, the D-value is the reduced energy of the system under the corresponding force state. The D-value of elastic energy increased from $8.05 E+06 \mathrm{~J}$ to $9.32 E+08 \mathrm{~J}$, indicating that with the increase in $P_{1}$, the release energy increased gradually and correspondingly. Although the increment of $P_{1}$ is all $1 \mathrm{MPa}$, the release elastic energy $(W)$ from FSF to LSF increases gradually from the beginning $3.71 E+05 \mathrm{~J}\left(P_{1}\right.$ increased from $20 \mathrm{MPa}$ to $21 \mathrm{MPa})$ to the last $2.42 E+08 \mathrm{~J}\left(P_{1}\right.$ increased from $57 \mathrm{MPa}$ to $58 \mathrm{MPa}$ ).

In order to see the trend of energy change under different force states more intuitively, we draw a change curve of the energy data, as shown in Figure 5, and we can clearly see that, with the increase in $P_{1}$, the storage elastic energies of the two models are all increasing, but the increasing speed is different; the greater the stress is, the greater the difference between them is. The $\mathrm{D}$-value of elastic energy shows different growth rates with the increase in $P_{1}$; before $P_{1}=40 \mathrm{MPa}$, the rate is small, and the reduced energy is magnitude of $10^{6}-10^{7} \mathrm{~J}$; between $P_{1}=40 \mathrm{MPa}$ and $50 \mathrm{MPa}$, the rate is increased, and the reduced energy is magnitude of $10^{7}-10^{8} \mathrm{~J}$, but after $P_{1}=50 \mathrm{MPa}$, the growth rate is obviously accelerated, and the reduced energy reach magnitude of $10^{8} \mathrm{~J}$.

The release elastic energy from FSF to LSF is shown in Figure 6. The magnitude of release energy is obviously different under different force states although the increment of $P_{1}$ is the same (1 MPa). The release energy curve should be divided into three stages, namely, "pregnant period," "growth period," and "upheaval period," respectively. In the pregnant stage, the release energy is mainly less than a magnitude of $10^{6} \mathrm{~J}$, and the corresponding $P_{1}$ is less than $49 \mathrm{MPa}$. In the growth stage, the release energy is mainly at a magnitude of $10^{7} \mathrm{~J}$, and the corresponding $P_{1}$ is between $50 \mathrm{MPa}$ and $54 \mathrm{MPa}$, but in the upheaval period, when $P_{1}$ is big than $54 \mathrm{MPa}$, the release energy magnitude reaches $10^{8} \mathrm{~J}$.

Based on the above numerical simulation results, we can easily find that the main energy source of rock burst is the release of elastic energy of surrounding rock, which is the same as classical energy theory, but our results indicate that 


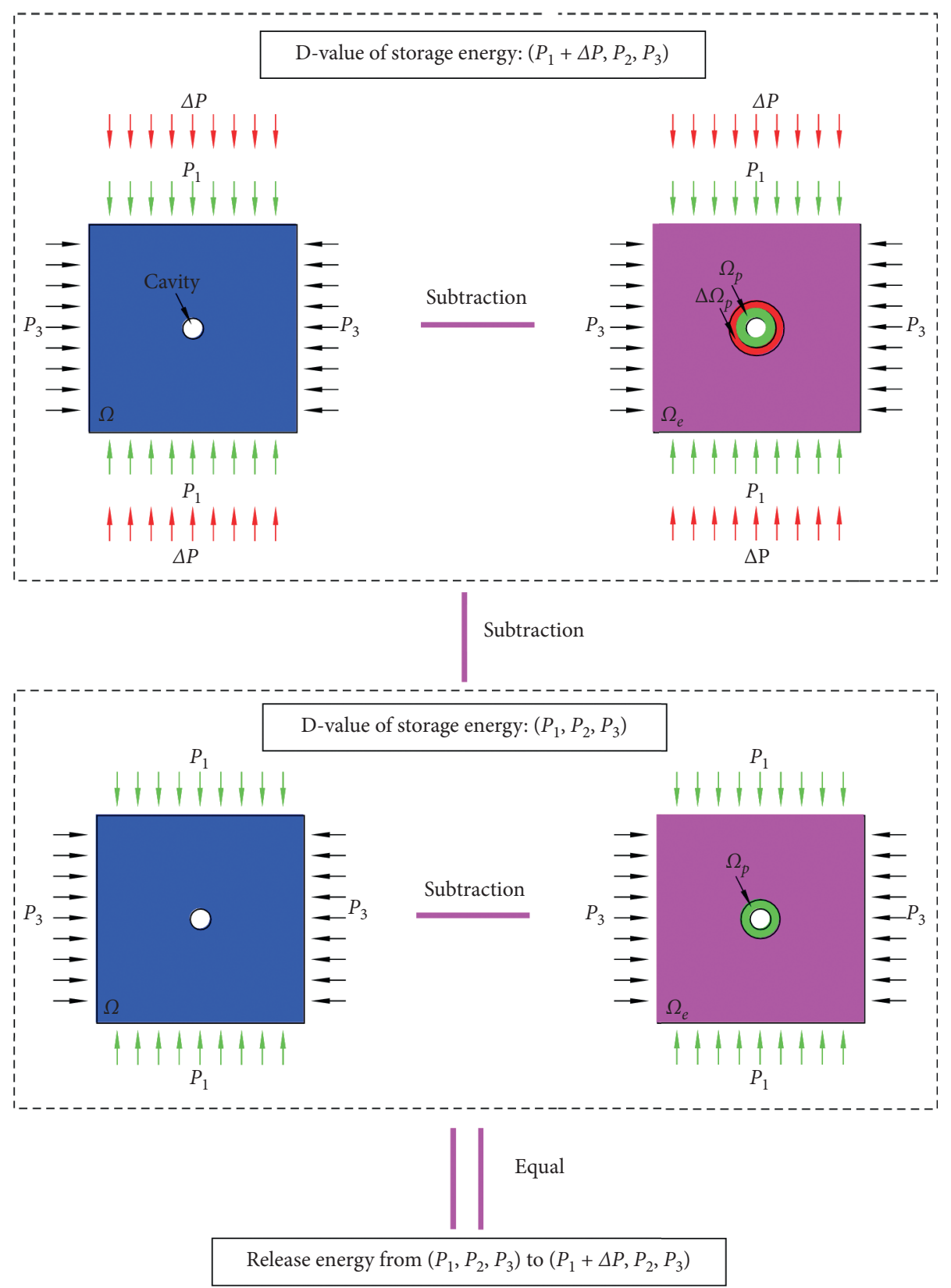

FIGURE 1: Calculation method of release energy when force state changes.

the main source of energy released is the release energy of plastic zone, which are more specific. The more important conclusion is that $\Delta P$ has a greater probability of causing rock burst under the FSF condition of bias force field. The larger the $P_{1} / P_{3}$ ratio of bias force field is, the greater the energy generated by the rock burst is, especially when the $P_{1} / P_{3}$ ratio is above 2.5 .

\section{Discussion}

We know that the magnitude of release energy during occurrence of rock burst is basically $10^{7}-10^{8} \mathrm{~J}[39,40]$. The thickness of the system in our calculation method is $1 \mathrm{~m}$, which means that our calculation result of the release energy is $1 \mathrm{~m}$ thick, while rock burst often causes tens to hundreds of meters of roadway damage. Taking $100 \mathrm{~m}$ failure length as an example, the elastic wave energy received by the MS system during the occurrence of rock burst is assumed to be $10^{8} \mathrm{~J}$, so the elastic wave energy per meter is $10^{6} \mathrm{~J}$. According to the calculation results in Results, the release energy is $10^{6} \mathrm{~J}$ in the pregnant stage; considering $\beta$ is $1 \%-10 \%$, the elastic wave energy is $10^{4}-10^{5} \mathrm{~J}$; similarly, the elastic wave energy of growth stage and upheaval stage is $10^{5}-10^{6} \mathrm{~J}$ and $10^{6}-10^{7} \mathrm{~J}$, respectively. From the results, we can see that if $\Delta P$ is $1 \mathrm{MPa}$, the occurrence of rock burst is mainly in the growth stage and upheaval stage. The $P_{1} / P_{3}$ ratios of growth stage and upheaval stage are all bigger than 2.5 (bias force field), and the shape of the plastic zone is "butterfly," which seems to be the precondition for the occurrence of rock burst. In order to better explain the issue, in this chapter, we mainly discuss the 


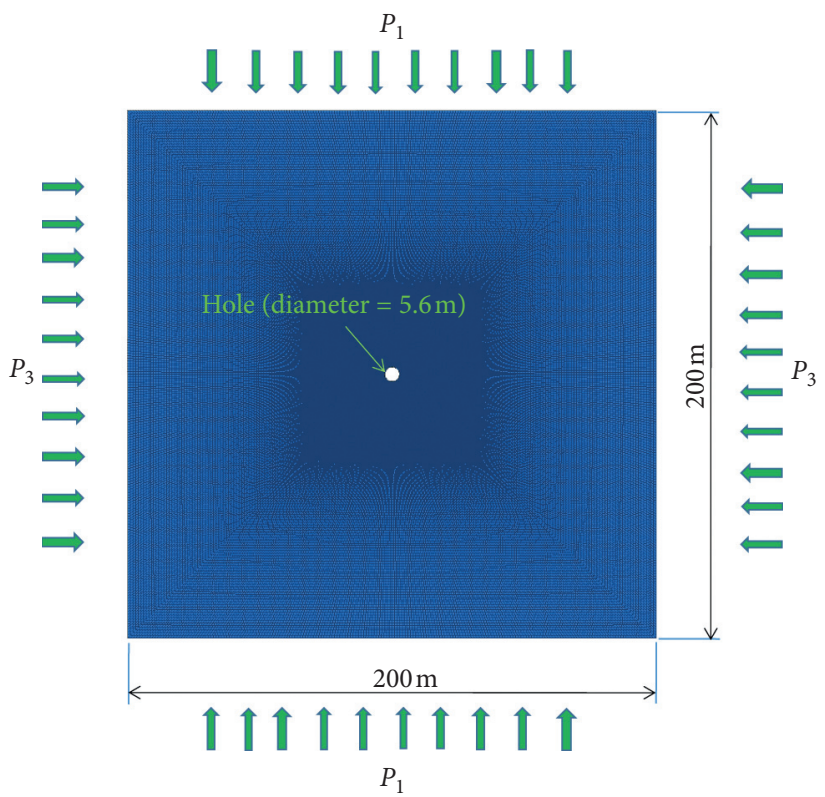

FIgUre 2: Calculation model of FLAC ${ }^{3 \mathrm{D}}$.

theoretical calculation of plastic zone, the magnitude of $\Delta P$, and the release energy under the condition of nonbias force field.

4.1. Theoretical Calculation of Plastic Zone. Our scientific research team [12] has already obtained the theoretical calculation of plastic zone distribution under different force fields and applied to reveal the mechanism of earthquake [41-43]. The theoretical recessive formula of plastic zone boundary around a circular hole (model as Figure 7) is shown in the following equation:

$$
\begin{aligned}
& 9\left(1-\eta^{2}\right)\left(\frac{a}{r}\right)^{8}\left[-12\left(1-\eta^{2}\right)+6\left(1-\eta^{2}\right) \cos 2 \theta\right]\left(\frac{a}{r}\right)^{6} \\
& +\left[10\left(1-\eta^{2}\right) \cos ^{2} 2 \theta-4\left(1-\eta^{2}\right) \sin ^{2} \varphi \cos ^{2} 2 \theta-2\left(1-\eta^{2}\right) \sin ^{2} 2 \theta-4\left(1-\eta^{2}\right) \cos 2 \theta+(1+\eta)^{2}\right]\left(\frac{a}{r}\right)^{4} \\
& +\left[-4(1-\eta)^{2} \cos 4 \theta+2\left(1-\eta^{2}\right) \cos 2 \theta-4\left(1-\eta^{2}\right) \sin ^{2} \varphi \cos 2 \theta-\frac{4 C(1-\eta) \sin 2 \varphi \cos 2 \theta}{P_{3}}\right]\left(\frac{a}{r}\right)^{2}
\end{aligned}
$$

where $a$ is the radius of the circular hole, $r$ and $\theta$ are the polar coordinates of any point on the boundary of plastic zone, $\eta$ is $P_{1} / P_{3}$, C is the cohesion of rock, and $\varphi$ is the internal friction angle of rock.

According to the theoretical formula, the calculated plastic zone results under different force states corresponding to Figure 3 are obtained as Figure 8. By comparing the two figures, we can find that the shape of plastic zone is basically the same in theoretical calculation and numerical simulation. The slight difference in the degree of smoothness is mainly due to the consideration of deformation compatibility equation in numerical simulation. Under the same basic conditions of numerical simulation, we get the change curve of the maximum radius $\left(R_{\max }\right)$ and area $(S)$ of plastic zone with change in $P_{1}$ under the theoretical calculation, as shown in Figure 9. From the results, we can see that the change trend of $R_{\max }$ and $S$ is different, but the overall change trend is the same as the release energy curve obtained by numerical simulation, especially after the "butterfly" shape state $\left(P_{1}=50 \mathrm{MPa}\right.$ and $\left.\eta=2.5\right)$, and the theoretical calculation also shows that when $\eta$ is $2.93, R_{\max }$ and $S$ of the system will be very large.

The occurrence of rock burst is often a moment of huge damage, and our results of energy release by numerical simulation and results of plastic zones calculated by theoretical calculation can explain the disaster obviously. That is to say, under the action of certain $\Delta P$, the elastic energy of surrounding rocks is released instantaneously, which causes part of surrounding rocks to be thrown out. The occurrence of rock burst is more likely to occur under the condition of bias force field because small $\Delta P$ can produce huge energy release under this condition. 


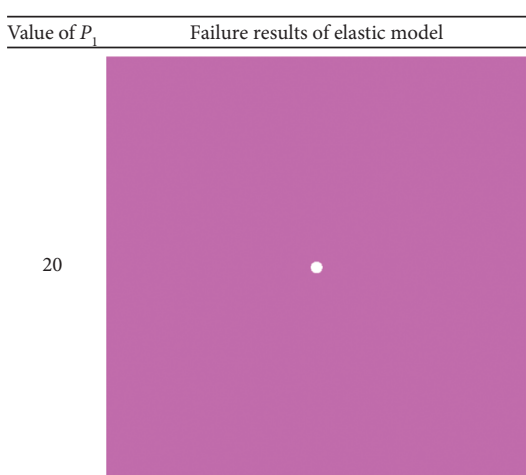

(a)

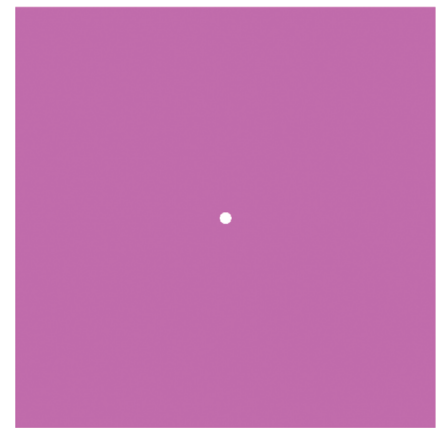

(c)

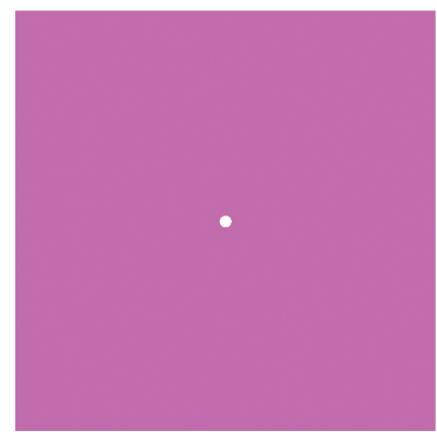

(e)

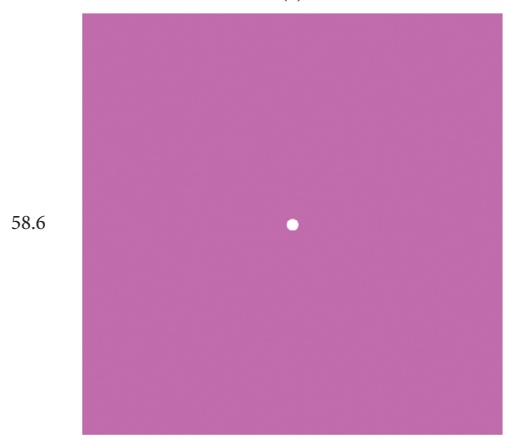

(g)

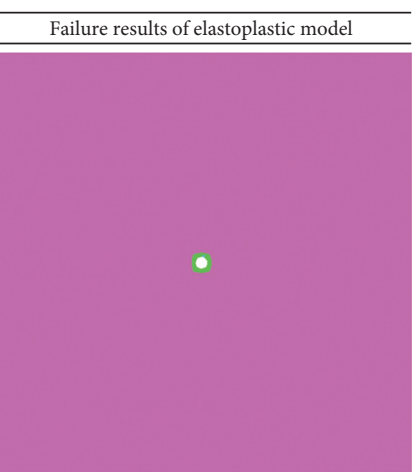

(b)

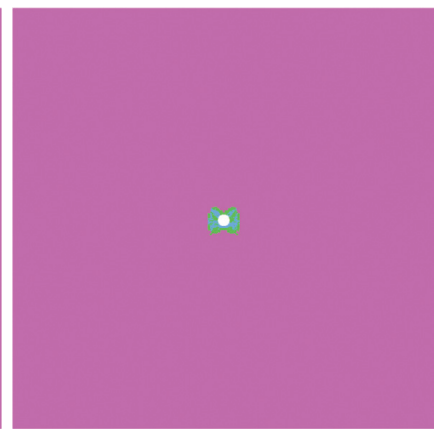

(d)

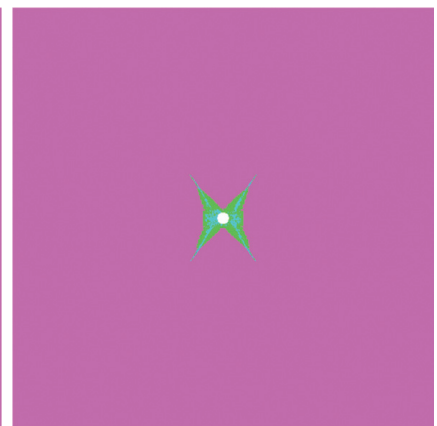

(f)

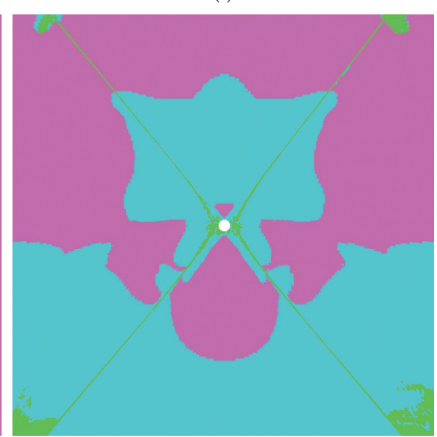

(h)

\footnotetext{
None

ㄴ Shear-n

ㄴ Shear-n shear-p
}

FIGURE 3: Failure results comparison of elastic model and elastoplastic model.

4.2. Triggering Stress. Another key point of the problem is how large $\Delta P$ is, which is directly related to whether it can cause system to the energy standard of rock burst under certain FSFs. We have consulted some references and carried out a study by means of theoretical calculation and MS monitoring. Generally, the elastic wave is divided into $\mathrm{P}$-wave and $\mathrm{S}$-wave; $\mathrm{P}$-wave is a longitudinal wave, and $\mathrm{S}$-wave is a shear wave. The stress increment generated by P-wave $\left(\sigma_{\mathrm{dP}}\right)$ and S-wave $\left(\sigma_{\mathrm{ds}}\right)$ can be calculated by the following equations [34]: 


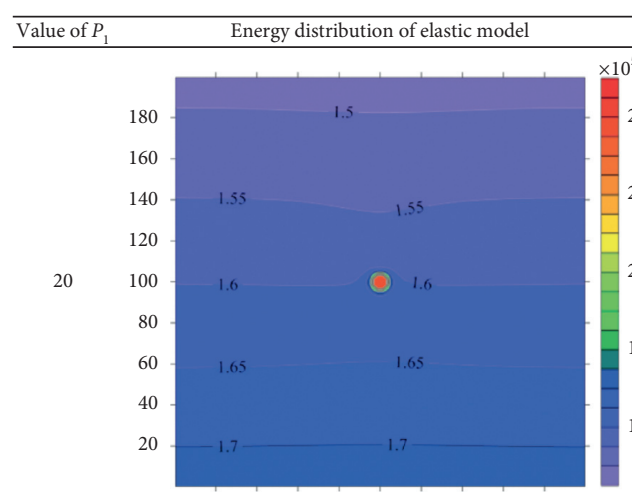

$\begin{array}{lllllllll}20 & 40 & 60 & 80 & 100 & 120 & 140 & 160 & 180\end{array}$

(a)

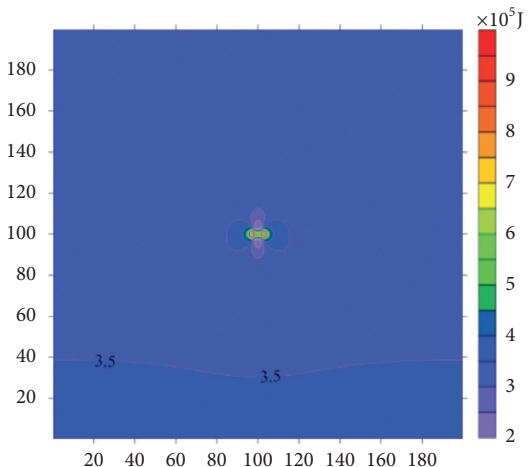

$\begin{array}{lllllllll}20 & 40 & 60 & 80 & 100 & 120 & 140 & 160 & 180\end{array}$

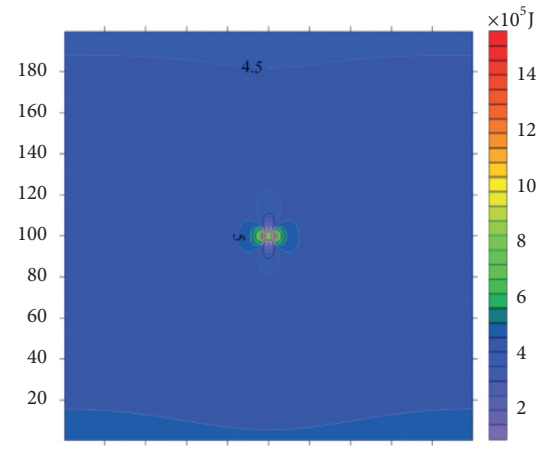

$\begin{array}{lllllllll}20 & 40 & 60 & 80 & 100 & 120 & 140 & 160 & 180\end{array}$ (e)

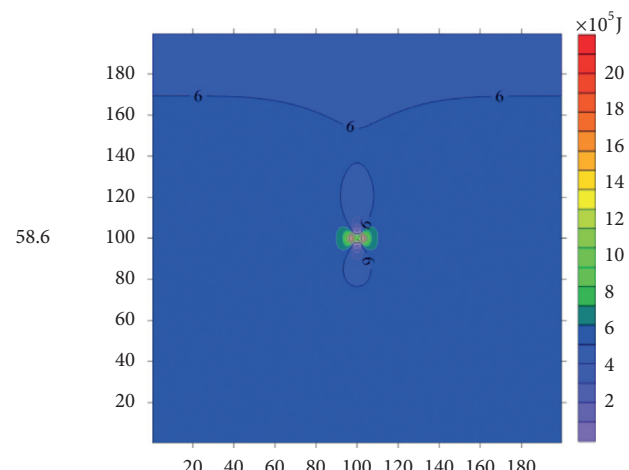

$\begin{array}{lllllllll}20 & 40 & 60 & 80 & 100 & 120 & 140 & 160 & 180\end{array}$

(g)

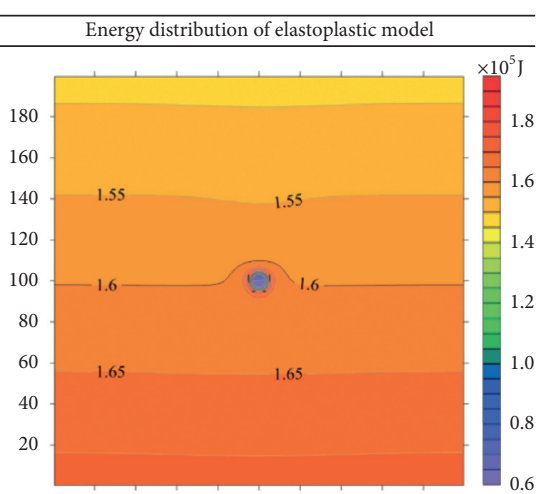

$\begin{array}{lllllllll}20 & 40 & 60 & 80 & 100 & 120 & 140 & 160 & 180\end{array}$

(b)

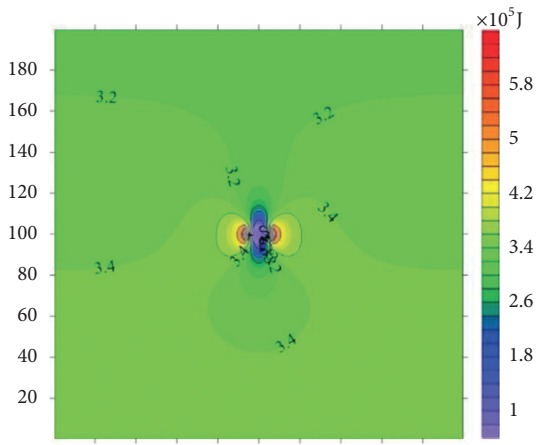

$\begin{array}{lllllllll}20 & 40 & 60 & 80 & 100 & 120 & 140 & 160 & 180\end{array}$

(d)

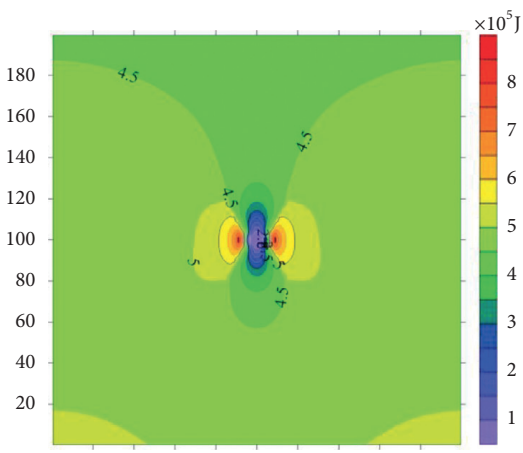

$\begin{array}{lllllllll}20 & 40 & 60 & 80 & 100 & 120 & 140 & 160 & 180\end{array}$

(f)

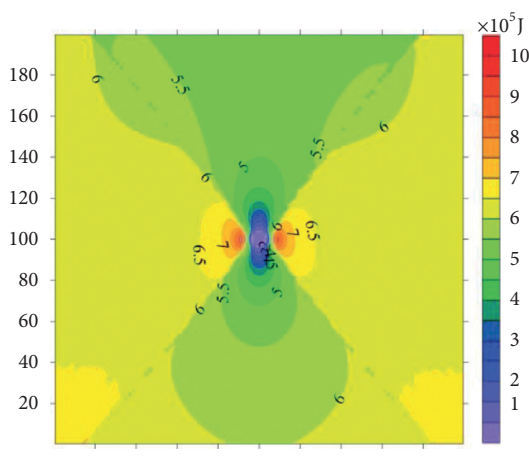

$\begin{array}{lllllllll}20 & 40 & 60 & 80 & 100 & 120 & 140 & 160 & 180\end{array}$

(h)

FIGURE 4: Energy distribution comparison of elastic model and elastoplastic model. 
TABLE 1: Energy calculation results of elastic model, elastoplastic model, and release elastic energy.

\begin{tabular}{|c|c|c|c|c|}
\hline $\begin{array}{l}\text { Value of } \\
\mathrm{P}_{1}\end{array}$ & $\begin{array}{l}\text { Storage energy of elastic model } \\
\left(\mathrm{U}_{\mathrm{FSF}}, \mathrm{U}_{\mathrm{LSF}}\right)\end{array}$ & $\begin{array}{l}\text { Storage energy of elastoplastic model } \\
\left(U_{\mathrm{FSF}}^{\prime}, U_{\mathrm{LSF}}^{\prime}\right)\end{array}$ & $\begin{array}{l}\text { D-value of energy } \\
\quad\left(D_{\mathrm{FSF}}, \mathrm{D}_{\mathrm{LSF}}\right)\end{array}$ & $\begin{array}{c}\text { Release energy from FSF to } \\
\text { LSF (W) }\end{array}$ \\
\hline 20 & $6.40 E+09$ & $6.39 E+09$ & $8.05 E+06$ & \\
\hline 21 & $6.62 E+09$ & $6.61 E+09$ & $8.42 E+06$ & $3.71 E+05$ \\
\hline 22 & $6.85 E+09$ & $6.84 E+09$ & $9.06 E+06$ & $6.40 E+05$ \\
\hline 23 & $7.10 E+09$ & $7.09 E+09$ & $9.96 \mathrm{E}+06$ & $9.00 E+05$ \\
\hline 24 & $7.36 E+09$ & $7.35 E+09$ & $1.07 E+07$ & $7.48 E+05$ \\
\hline 25 & $7.64 E+09$ & $7.63 E+09$ & $1.16 E+07$ & $9.32 E+05$ \\
\hline 26 & $7.93 E+09$ & $7.91 E+09$ & $1.27 E+07$ & $1.05 E+06$ \\
\hline 27 & $8.23 E+09$ & $8.21 E+09$ & $1.37 E+07$ & $9.98 E+05$ \\
\hline 28 & $8.55 E+09$ & $8.53 E+09$ & $1.51 E+07$ & $1.43 E+06$ \\
\hline 29 & $8.87 E+09$ & $8.86 E+09$ & $1.62 E+07$ & $1.12 E+6$ \\
\hline 30 & $9.22 E+09$ & $9.20 E+09$ & $1.83 E+07$ & $2.09 E+06$ \\
\hline 31 & $9.58 E+09$ & $9.56 E+09$ & $2.03 E+07$ & $1.94 E+06$ \\
\hline 32 & $9.95 E+09$ & $9.93 E+09$ & $2.24 E+07$ & $2.08 E+06$ \\
\hline 33 & $1.03 E+10$ & $1.03 E+10$ & $2.48 E+07$ & $2.45 E+06$ \\
\hline 34 & $1.07 E+10$ & $1.07 E+10$ & $2.77 E+07$ & $2.88 E+06$ \\
\hline 35 & $1.11 E+10$ & $1.11 E+10$ & $3.08 E+07$ & $3.10 E+06$ \\
\hline 36 & $1.16 E+10$ & $1.15 E+10$ & $3.42 E+07$ & $3.39 E+06$ \\
\hline 37 & $1.20 E+10$ & $1.20 E+10$ & $3.79 E+07$ & $3.70 E+06$ \\
\hline 38 & $1.25 E+10$ & $1.24 E+10$ & $4.12 E+07$ & $3.34 E+06$ \\
\hline 39 & $1.29 E+10$ & $1.29 E+10$ & $4.57 E+07$ & $4.46 E+06$ \\
\hline 40 & $1.34 E+10$ & $1.34 E+10$ & $5.01 \mathrm{E}+07$ & $4.40 E+06$ \\
\hline 41 & $1.39 E+10$ & $1.39 E+10$ & $5.47 E+07$ & $4.61 E+06$ \\
\hline 42 & $1.44 E+10$ & $1.44 E+10$ & $5.99 E+07$ & $5.18 E+06$ \\
\hline 43 & $1.49 E+10$ & $1.49 E+10$ & $6.50 E+07$ & $5.17 E+06$ \\
\hline 44 & $1.55 E+10$ & $1.54 E+10$ & $7.15 E+07$ & $6.43 E+06$ \\
\hline 45 & $1.60 E+10$ & $1.60 E+10$ & $7.87 E+07$ & $7.25 E+06$ \\
\hline 46 & $1.66 E+10$ & $1.65 E+10$ & $8.69 E+07$ & $8.19 E+06$ \\
\hline 47 & $1.72 E+10$ & $1.71 E+10$ & $9.70 E+07$ & $1.00 E+07$ \\
\hline 48 & $1.78 E+10$ & $1.77 E+10$ & $1.08 E+08$ & $1.10 E+07$ \\
\hline 49 & $1.84 E+10$ & $1.83 E+10$ & $1.21 E+08$ & $1.27 E+07$ \\
\hline 50 & $1.90 E+10$ & $1.89 E+10$ & $1.40 E+08$ & $1.93 E+07$ \\
\hline 51 & $1.96 E+10$ & $1.95 E+10$ & $1.66 E+08$ & $2.57 E+07$ \\
\hline 52 & $2.03 E+10$ & $2.01 E+10$ & $2.02 E+08$ & $3.63 E+07$ \\
\hline 53 & $2.09 E+10$ & $2.07 E+10$ & $2.46 E+08$ & $4.42 E+07$ \\
\hline 54 & $2.16 E+10$ & $2.13 E+10$ & $3.07 E+08$ & $6.04 E+07$ \\
\hline 55 & $2.23 E+10$ & $2.19 E+10$ & $3.91 E+08$ & $8.39 E+07$ \\
\hline 56 & $2.30 E+10$ & $2.25 E+10$ & $5.34 E+08$ & $1.43 E+08$ \\
\hline 57 & $2.37 E+10$ & $2.30 E+10$ & $6.90 E+08$ & $1.56 E+08$ \\
\hline 58 & $2.44 E+10$ & $2.35 E+10$ & $9.32 E+08$ & $2.42 E+08$ \\
\hline
\end{tabular}

$$
\begin{aligned}
& \sigma_{\mathrm{dP}}=\frac{(1+\mu)(1-2 \mu)}{(1-\mu)} \rho C_{P} v_{\mathrm{pp}}, \\
& \sigma_{\mathrm{dP}}=\rho C_{S} v_{\mathrm{ps}},
\end{aligned}
$$

where $\rho$ is the density of medium; $C_{P}$ and $C_{S}$ are the propagation velocities of $\mathrm{P}$-wave and $\mathrm{S}$-wave, respectively; and $v_{\mathrm{pp}}$ and $v_{\mathrm{ps}}$ are the peak particle velocity (PPV [44]) of $\mathrm{P}$-wave and $\mathrm{S}$-wave, respectively.

Suppose $\mu=0.29, \rho=1400 \mathrm{~kg} / \mathrm{m}^{3}, C_{P}=3500 \mathrm{~m} / \mathrm{s}$, and $C_{S}=2100 \mathrm{~m} / \mathrm{s}$ (propagation speed of the $\mathrm{S}$-wave is about 0.6 times of the P-wave [45]); the maximum PPV is $1 \mathrm{~m} / \mathrm{s}$ according to a relevant study $[40,46]$. By calculation, the maximum of $\sigma_{d P}$ and $\sigma_{d S}$ can reach $3.74 \mathrm{MPa}$ and $2 \mathrm{MPa}$, respectively. In fact, PPV measured by the MS system in a coal mine rarely reaches $1 \mathrm{~m} / \mathrm{s}$, the maximum value of PPV is
$0.3 \mathrm{~m} / \mathrm{s}$ according to the measured results in Poland [39], and the majority of PPV is about $0.0001 \mathrm{~m} / \mathrm{s}$ to $0.1 \mathrm{~m} / \mathrm{s}$ in the MS measurement results for half a year in a coal mine in Poland. If the maximum value of $P P V$ is $0.3 \mathrm{~m} / \mathrm{s}$, the maximum of $\sigma_{d P}$ and $\sigma_{d s}$ can only reach $1.12 \mathrm{MPa}$ and $0.88 \mathrm{MPa}$, respectively.

When $\sigma_{d P}$ reaches $3 \mathrm{MPa}$ in the pregnant stage, it can trigger the release energy of $10^{7} \mathrm{~J}$, and the energy level may lead to the occurrence of rock burst, according to the analysis of Results. Similarly, when $\sigma_{d P}$ reaches $1 \mathrm{MPa}$ in the growth period or $\sigma_{d P}$ reaches $0.1 \mathrm{MPa} \sim 1 \mathrm{MPa}$ in the upheaval period, it may lead to the occurrence of rock burst. Therefore, we should monitor and forewarn the rock burst according to the FSF of roadway and the result of MS monitoring, instead of only relying on the MS system to reach a certain energy level. Through backcalculation, we get 


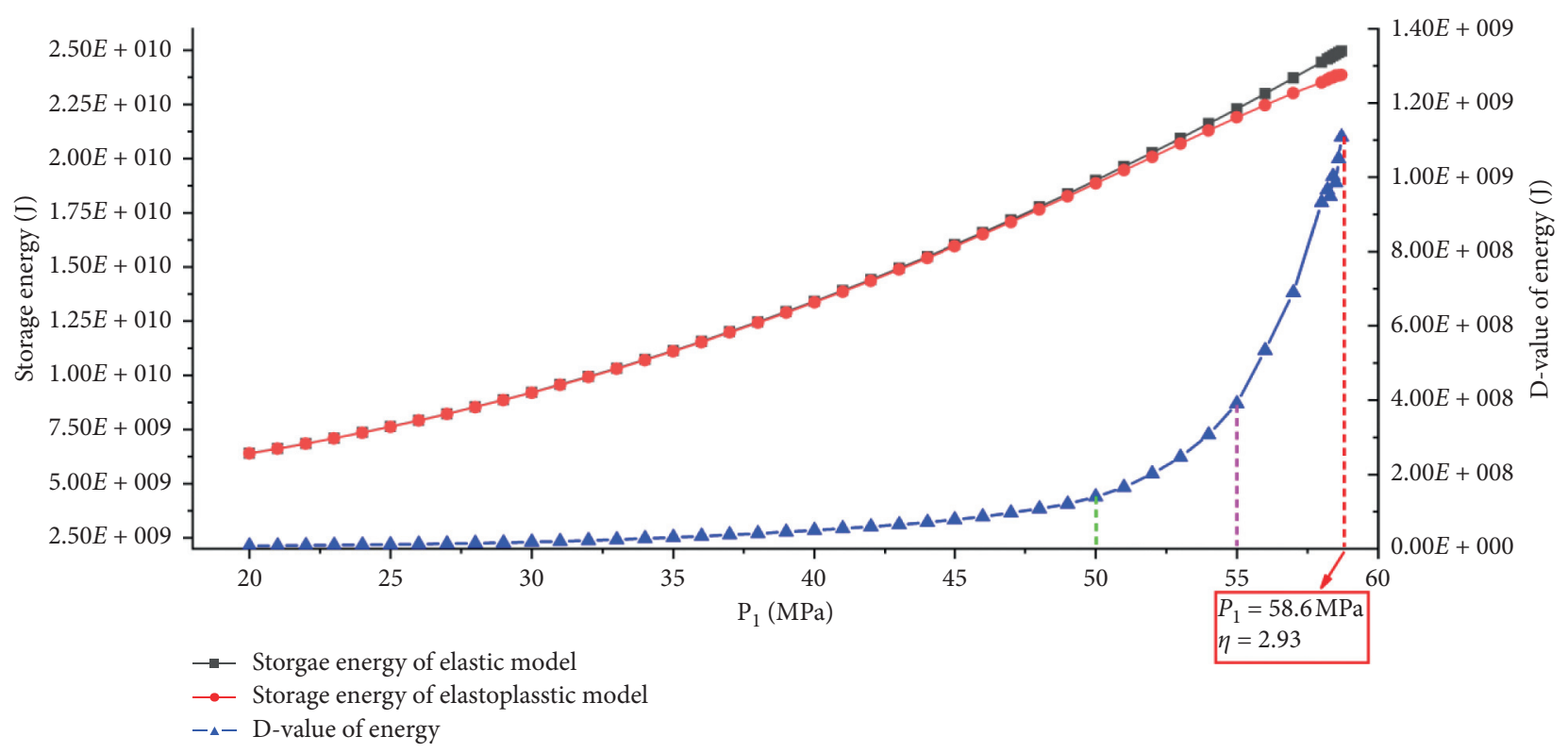

FIGURE 5: Energy calculation results of elastic model, elastoplastic model, and D-value of energy.

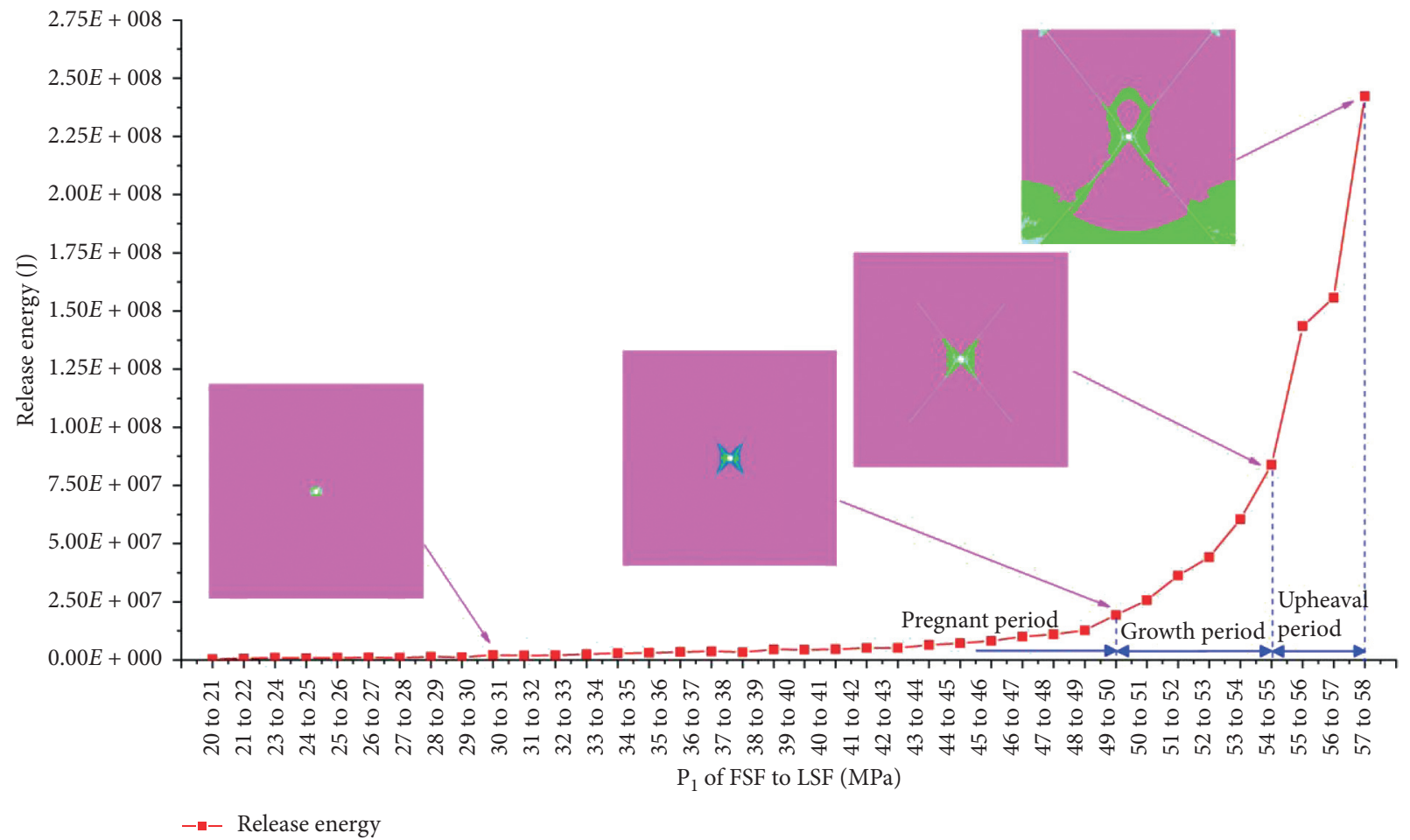

FiguRE 6: Release energy under different FSF (FSF to LSF).

the critical criterion of rock burst under different FSFs, as shown in Table 2.

4.3. Comparison of Nonbias Force Field Release Energy. In order to better explain that the bias force field is the main factor of rock burst, we carried out numerical simulation under the condition of uniform force field and formed
Figure 10. Under the condition of uniform force field, the storage elastic energy of the elastic model and the elastoplastic model is all increasing, which is the same as the bias force field, but the D-value of elastic energy is obviously different from the bias force field, and it does not show any increase in the rate of change, which shows that the energy released from FSF to LSF does not increase under the uniform force field. The release energy level of $10^{7} \mathrm{~J}$ can be achieved only when the 


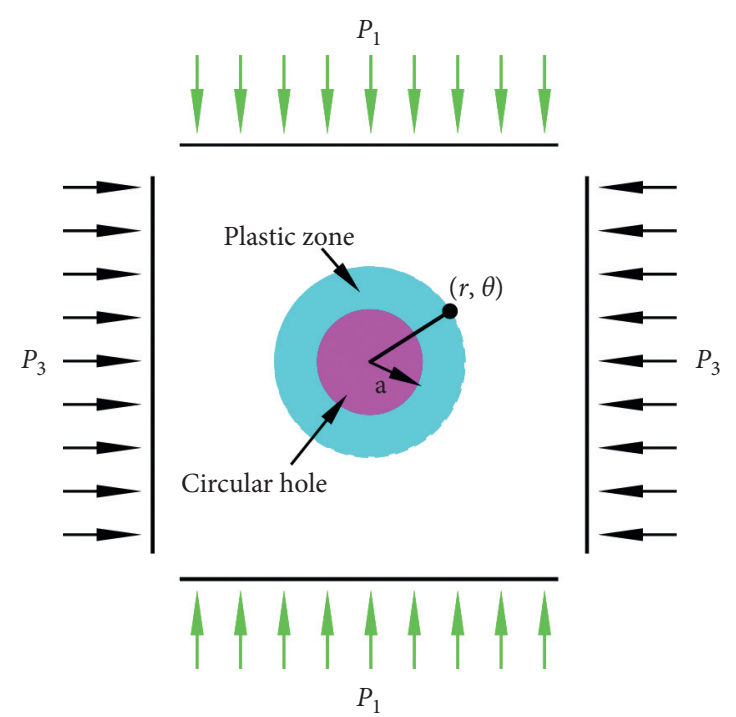

FIgURE 7: Theoretical calculation model.
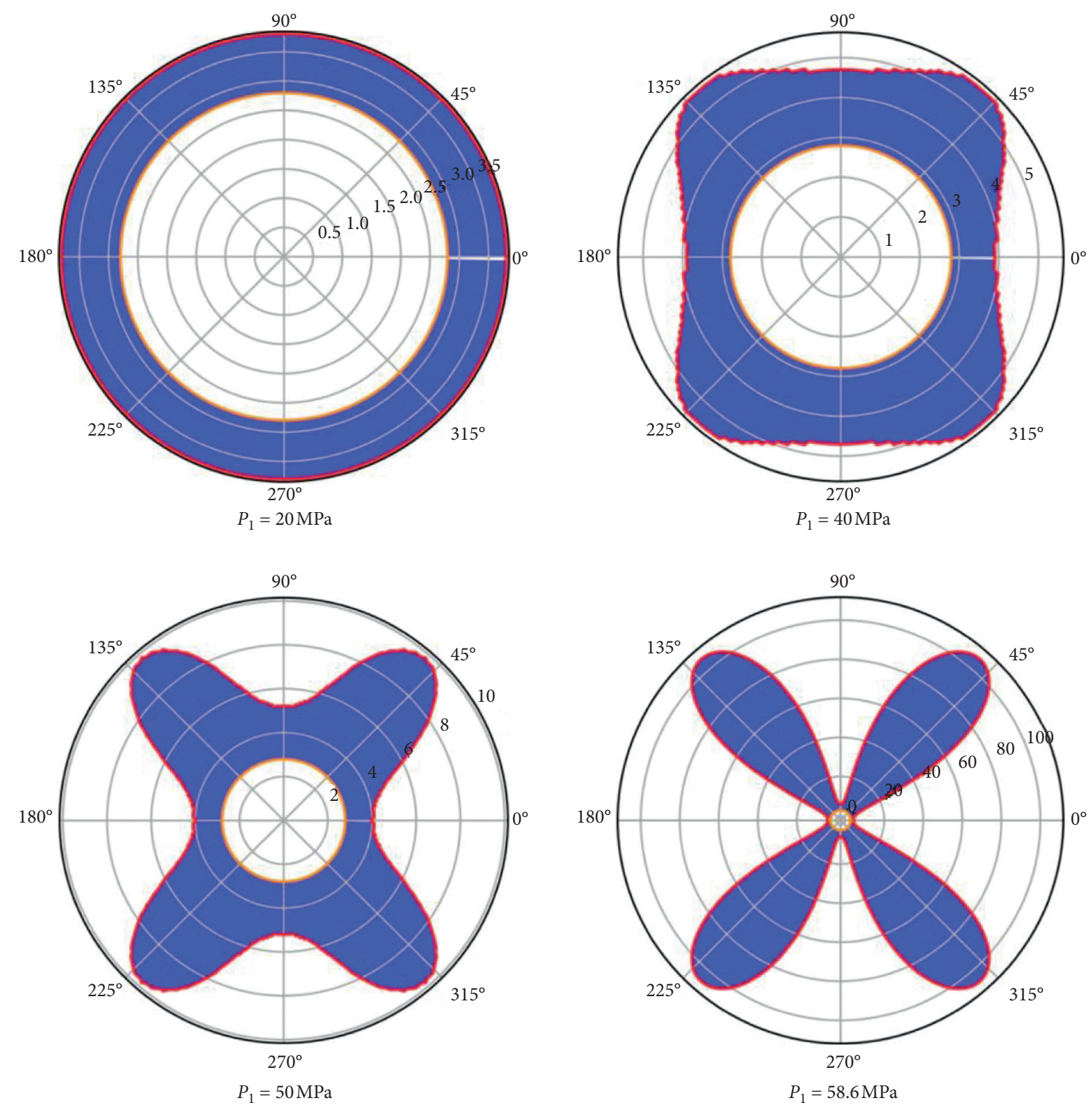

Figure 8: Theoretical failure results of elastoplastic model: (a) $P_{1}=20 \mathrm{MPa}$; (b) $P_{1}=40 \mathrm{MPa}$; (c) $P_{1}=50 \mathrm{MPa}$; (d) $P_{1}=58.6 \mathrm{MPa}$. 


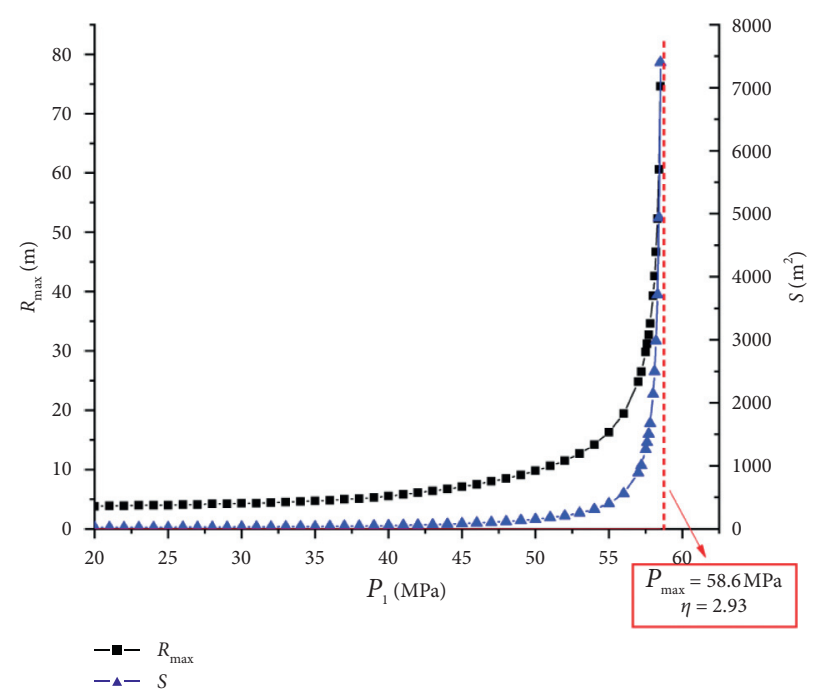

Figure 9: Theoretical change in the plastic zone under elastoplastic model ( $R_{\max }$ : maximum radius of plastic zone; $S$ : area of plastic zone).

TABLE 2: Critical criterion of rock burst under different FSF values.

\begin{tabular}{lccc}
\hline Stage & $P_{1} / P_{3}$ ratio of FSF & Critical $\Delta P$ value $(\mathrm{MPa})$ & Critical PPV value $(\mathrm{m} / \mathrm{s})$ \\
\hline Pregnant stage & 1 to 2.5 & $>3$ & $>0.8$ \\
Growth period & 2.5 to 2.75 & $>1$ & $>0.27$ \\
Upheaval period & 2.75 to 2.93 & $>0.1-1$ & $>0.027$ \\
\hline
\end{tabular}

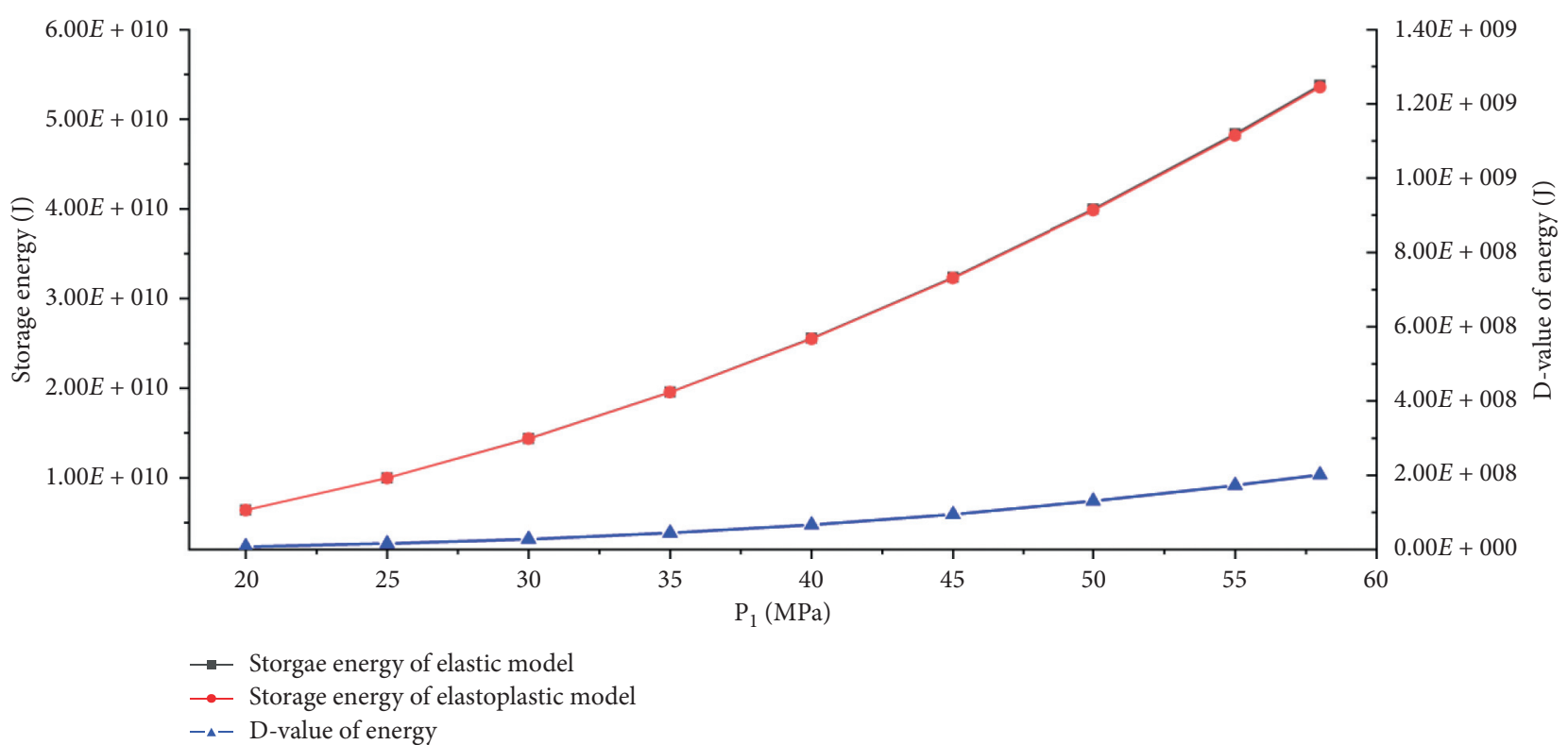

FIGURE 10: Energy calculation results of elastic model, elastoplastic model, and D-value of energy under uniform force field.

forces in three directions are all increased by $5 \mathrm{MPa}$, but this kind of $\Delta P$ basically does not exist.

Figure 11 shows the statistics of release energy under different FSF and $\Delta P$ conditions. If FSF is $P_{1}=P_{2}=P_{3}=40 \mathrm{MPa}$ and $\Delta P=1 \mathrm{MPa}$, the release energy is $1.86 E+06 \mathrm{~J}$; if FSF is small ratio bias force $\left(P_{1} / P_{3}=1.5\right)$ and $\Delta P=1 \mathrm{MPa}$, the release energy is $1.94 E+06 \mathrm{~J}$, and the energy magnitude is not met in with the occurrence of rock burst. While if FSF is big ratio bias force $\left(P_{1} / P_{3}=2.75\right)$ and
$\Delta P=1 \mathrm{MPa}$, the release energy is $1.43 E+08 \mathrm{~J}$, which will probably lead to rock burst; if FSF is huge ratio bias force $\left(P_{1} / P_{3}=2.92\right)$, only $\Delta P=0.2 \mathrm{MPa}$ is needed, which will result in the energy release of $4.78 E+07 \mathrm{~J}$ and probably lead to rock burst. This fully proves a preliminary fact that high force field is not terrible, and the real danger is bias force field.

From the above analysis, it is fully confirmed that FSF is the main reason for the occurrence of rock burst, while $\Delta P$ is 

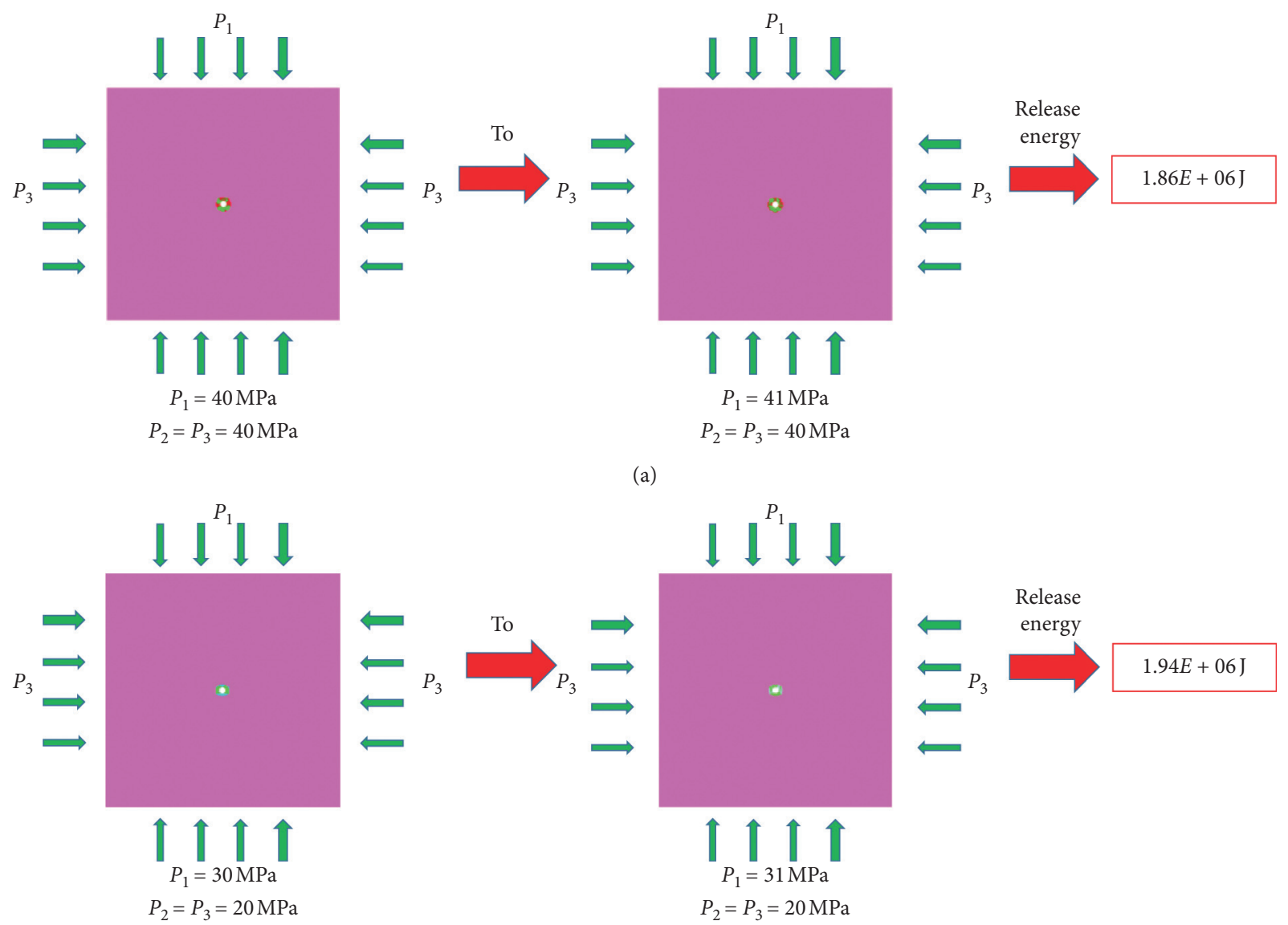

(a)

)
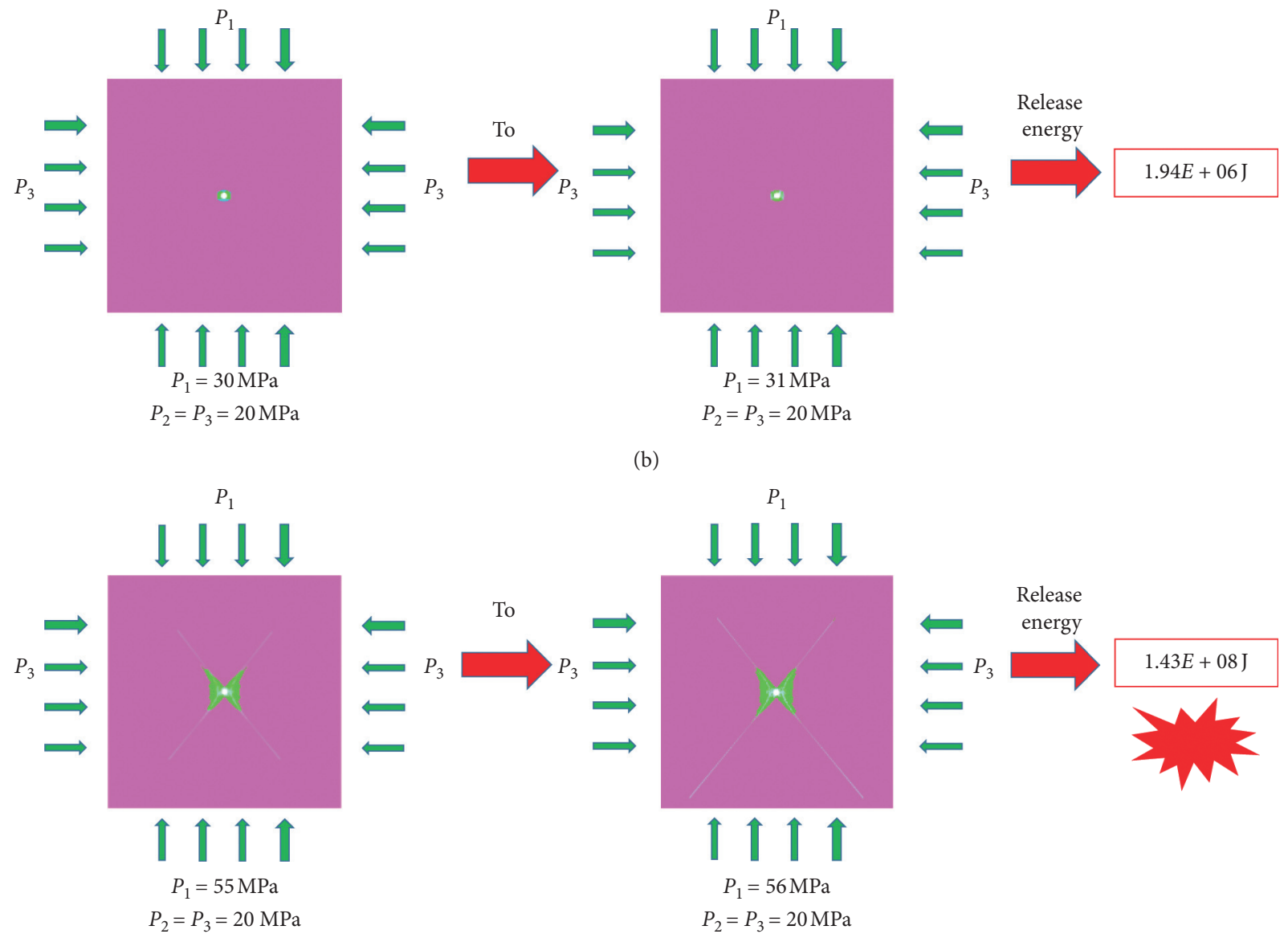

(b)
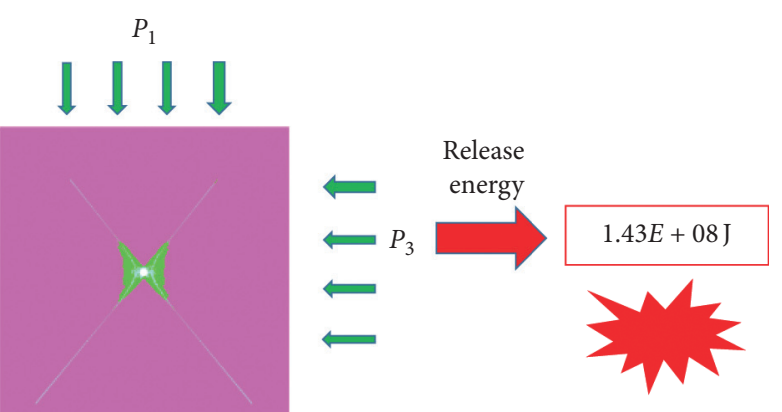

$$
\begin{gathered}
\Uparrow \Uparrow \Uparrow \\
P_{1}=56 \mathrm{MPa} \\
P_{2}=P_{3}=20 \mathrm{MPa}
\end{gathered}
$$

(c)

Figure 11: Continued. 


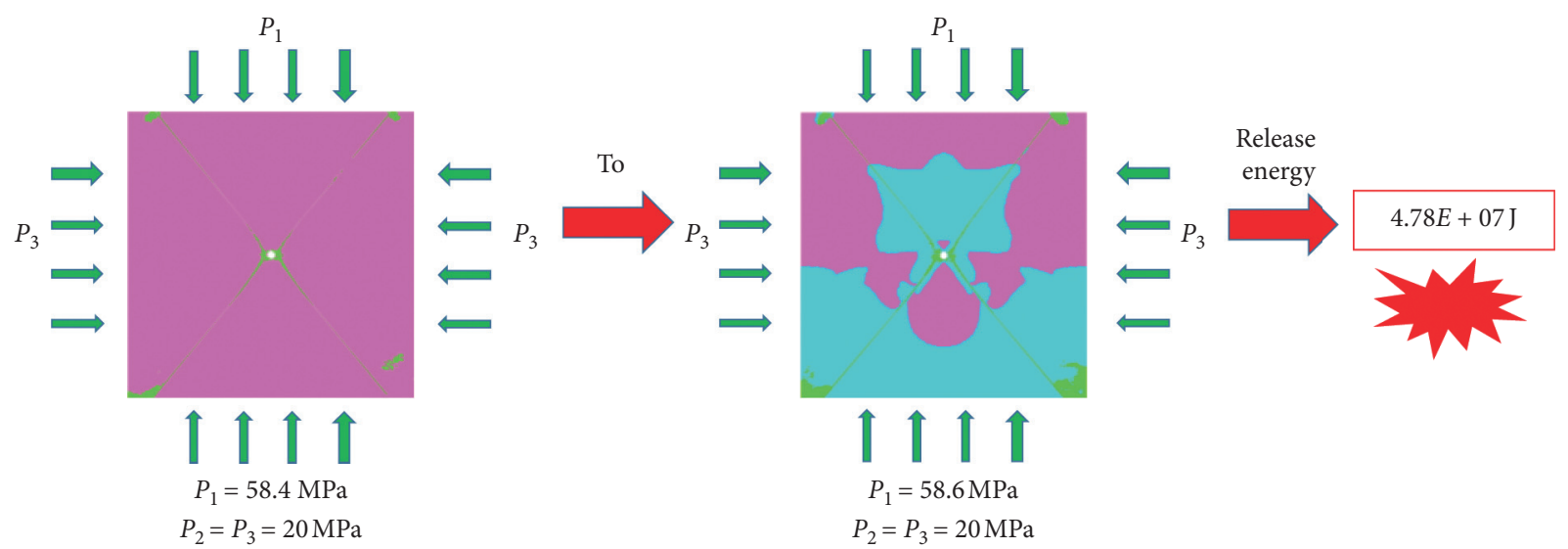

(d)

FiguRE 11: Release energy of different force fields and $\Delta P$ : (a) release energy of uniform force $\left(P_{1} / P_{3}=1.0\right)$ field $(\Delta P=1 \mathrm{MPa})$; (b) release energy of small ratio bias force $\left(P_{1} / P_{3}=1.5\right)$ field $(\triangle P=1 \mathrm{MPa})$; (c) release energy of large ratio bias force $\left(P_{1} / P_{3}=2.75\right)$ field $(\Delta P=1 \mathrm{MPa})$; (d) release energy of huge ratio bias force $\left(P_{1} / P_{3}=2.92\right)$ field $(\triangle P=0.2 \mathrm{MPa})$.

the secondary factor. When the combination of the two factors causes the release energy to reach a magnitude of $10^{7} \mathrm{~J}$, rock burst will be caused. This important discovery is of great significance to the monitoring of rock burst, indicating that the monitoring should not only focus on $\Delta P$, and the more important is FSF. It is also of great value to the governance of rock burst, which should aim to reduce the D-value energy of surrounding rock so that the energy can be released in advance; in other words, if the governance measures do not trigger the release of energy, it indicates that the governance measures are invalid. The only drawback is that our theory cannot be verified in the field at present (but a study [47] has confirmed the existence of butterfly damage in the laboratory) because the FSF of the roadway is difficult to measure, but we believe that, with the promotion of the theory, there will be corresponding stress measuring equipment for monitoring.

\section{Conclusion}

We put forward a method to calculate the release energy of surrounding rock system from one mechanical state to another. Through calculation, we mainly get the following conclusions:

(1) The mechanism of rock burst is that, under a certain FSF, $\Delta P$ causes the instantaneous release of elastic energy of surrounding rock system and brings about huge damage; the release energy mainly comes from units of elastic to plastic. Therefore, FSF and $\Delta P$ are the two factors that lead to the rock burst, and FSF should be the main factor.

(2) Under different FSF conditions, the same $\Delta P$ will lead to different energy releases, which is closely related to the $P_{1} / P_{3}$ ratio of FSF. Different FSFs are divided into three stages according to the ratio: pregnant period, growth period, and upheaval period. The $P_{1} / P_{3}$ ratio dividing points of the three stages are 2.5 and 2.75 .
(3) FSF and $\Delta P$ should be considered as the main factors in the monitoring and early warning of rock burst, and FSF should be the main factor. The $\Delta P$ of $3 \mathrm{MPa}$, $1 \mathrm{MPa}$, and $0.1 \mathrm{MPa}$ of the example case is the minimum value to cause rock burst of the three stages, respectively. It is speculated that most of the rock burst is produced in the growth period and upheaval period, unless the PPV is superlarge.

\section{Data Availability}

This paper is a basic theoretical study, using numerical simulation and theoretical calculation methods. If necessary, we can provide numerical simulation program.

\section{Conflicts of Interest}

The authors declare that they have no conflicts of interest.

\section{References}

[1] T.-B. Zhao, W.-Y. Guo, Y.-L. Tan, C.-P. Lu, and C.-W. Wang, "Case histories of rock bursts under complicated geological conditions," Bulletin of Engineering Geology and the Environment, vol. 77, no. 4, pp. 1529-1545, 2017.

[2] W. Zhang, X. Qu, C. Li et al., "Fracture analysis of multi-hard roofs based on microseismic monitoring and control techniques for induced rock burst: a case study," Arabian Journal of Geosciences, vol. 12, no. 24, 2019.

[3] P. G. Ranjith, J. Zhao, M. Ju, R. V. S. De Silva, T. D. Rathnaweera, and A. K. M. S. Bandara, "Opportunities and challenges in deep mining: a brief review," Engineering, vol. 3, no. 4, pp. 546-551, 2017.

[4] M. Can, "Coal bursts in the deep longwall mines of the United States," International Journal of Coal Science \& Technology, vol. 3, no. 1, pp. 1-9, 2016.

[5] T. B. Zan and W. Vu, "Failure of fractured rock," International Journal of Rock Mechanics and Mining Sciences \& Geomechanics Abstracts, vol. 20, 1969.

[6] N. G. W. Cook, "Rock mechanics applied to the study of rock burst," JSAft, vol. 8, no. 1, 1966. 
[7] B. H. G. Brady and E. T. Bnown, Rock Mechonics for Underground Mining, Geoge Allen and Univin Ltd, Crows Nest, Australia, 1985.

[8] T. B. Zan, "Mechanism of brittle of rocks. Part I, II and III," International Journal of Rock Mechanics and Mining Sciences \& Geomechanics Abstracts, vol. 48, no. 3, 1967.

[9] Q. Qi, Z. Ouyang, S. Zhao, H. Li, X. Li, and N. Zhang, "Study on types of rock burst mine and prevention methods in China," Coal Science and Technology, vol. 10, 2014.

[10] Y. Pan, "Disturbance response instability theory of rockburst in coal mine," Journal of China Coal Society, vol. 43, no. 8, pp. 2091-2098, 2018.

[11] Y. Li, "Mechanism of rock burst and its preliminary application," Journal of China Institute of Mining, vol. 3, pp. 37-43, 1985.

[12] N. Ma, X. Guo, Z. Zhao, X. Zhao, and H. Liu, "Occurrence mechanisms and judging criterion on circular tunnel butterfly rock burst in homogeneous medium," Journal of China Coal Society, vol. 11, pp. 2679-2688, 2016.

[13] Z. Zhao, N. Ma, X. Guo, X. Zhao, Y. Xia, and Z. Ma, "Mechanism conjecture of butterfly rock burst in coal seam roadway," Journal of China Coal Society, vol. 11, pp. 26892697, 2016.

[14] L.-M. Dou, Z.-L. Mu, Z.-L. Li, A.-Y. Cao, and S.-Y. Gong, "Research progress of monitoring, forecasting, and prevention of rockburst in underground coal mining in China," International Journal of Coal Science \& Technology, vol. 1, no. 3, pp. 278-288, 2014.

[15] L. Dou, J. He, A. Cao, S. Gong, and W. Cai, "Rock burst prevention methods based on theory of dynamic and static combined load induced in coal mine," Journal of China Coal Society, vol. 7, pp. 1469-1476, 2015.

[16] J. Pan, "Theory of rockburst start - up and its complete technology system," Journal of China Coal Society, vol. 44, no. 1, pp. 173-182, 2019.

[17] H. Haitjema, “Occam's razor," Groundwater, vol. 57, no. 3, p. 349, 2019.

[18] L. Jiang, Y. Zhao, N. Golsanami, L. Chen, and W. Yan, "A novel type of neural networks for feature engineering of geological data: case studies of coal and gas hydrate-bearing sediments," Geoscience Frontiers, vol. 11, no. 5, pp. 1511-1531, 2020.

[19] B.-Y. Jiang, S.-T. Gu, L.-G. Wang, G.-C. Zhang, and W.-S. Li, "Strainburst process of marble in tunnel-excavation-induced stress path considering intermediate principal stress," Journal of Central South University, vol. 26, no. 4, pp. 984-999, 2019.

[20] D. Song, Research on Rockburst Evolutionary Process and Energy Dissipation Characteristics, China University of Mining and Technology, Xuzhou, China, 2012.

[21] Y. Wang, B. Liu, and Y. Qi, "A risk evaluation method with an improved scale for tunnel engineering," Arabian Journal for Science and Engineering, vol. 43, no. 4, pp. 2053-2067, 2017.

[22] J. Ning, J. Wang, L. Jiang, N. Jiang, X. Liu, and J. Jiang, "Fracture analysis of double-layer hard and thick roof and the controlling effect on strata behavior: a case study," Engineering Failure Analysis, vol. 81, pp. 117-134, 2017.

[23] P. Wang, L. Jiang, J. Jiang, P. Zheng, and W. Li, "Strata behaviors and rock burst-inducing mechanism under the coupling effect of a hard, thick stratum and a normal fault," International Journal of Geomechanics, vol. 18, no. 2, 2018.

[24] Q. Wu, J. Jiang, Q. Wu, Y. Xue, P. Kong, and B. Gong, "Study on the fracture of hard and thick sandstone and the distribution characteristics of microseismic activity," Geotechnical and Geological Engineering, vol. 36, no. 6, pp. 3357-3373, 2018.

[25] L. Dong, Q. Hu, X. Tong, and Y. Liu, "Velocity-free ms/ae source location method for three-dimensional hole-containing structures," Engineering, vol. 29, 2020.

[26] J. He, "Combined application of wide-field electromagnetic method and flow field fitting method for high-resolution exploration: a case study of the anjialing No. 1 coal mine," Engineering, vol. 4, no. 5, pp. 667-675, 2018.

[27] C.-P. Lu, Y. Liu, H.-Y. Wang, and P.-F. Liu, "Microseismic signals of double-layer hard and thick igneous strata separation and fracturing," International Journal of Coal Geology, vol. 160-161, pp. 28-41, 2016.

[28] W. Guo, Q. Gu, Y. Tan, and S. Hu, "Case studies of rock bursts in tectonic areas with facies change," Energies, vol. 12, no. 7, 2019.

[29] G. Yang, F. Jiang, X. Qu, L. Li, Q. Wei, and N. Li, "Comprehensive monitoring and early warning technology for rock burst of tunneling face with thick coal seams," Chinese Journal of Geotechnical Engineering, vol. 41, no. 10, pp. 1949-1958, 2019.

[30] J. Shu, L. Jiang, P. Kong, P. Wang, and P. Zhang, "Numerical modeling approach on mining-induced strata structural behavior by considering the fracture-weakening effect on rock mass," Applied Sciences, vol. 9, no. 9, 2019.

[31] W. Zhang, C. Li, J. Ren, and Z. Wu, "Measurement and application of vibration signals during pressure relief hole construction using microseismic system," Measurement, vol. 21, 2020.

[32] Z. Liu, A. Cao, G. Liu, and J. Li, "Experimental research on stress relief of high-stress coal based on noncoupling blasting," Arabian Journal for Science and Engineering, vol. 43, no. 7, pp. 3717-3724, 2018.

[33] L. Jiang, P. Kong, J. Shu, and K. Fan, "Numerical analysis of support designs based on a case study of a longwall entry," Rock Mechanics and Rock Engineering, vol. 52, no. 9, pp. 3373-3384, 2019.

[34] H. He, L. Dou, J. Fan, T. Du, and X. Sun, "Deep-hole directional fracturing of thick hard roof for rockburst prevention," Tunnelling and Underground Space Technology, vol. 32, pp. 34-43, 2012.

[35] H. Xie, Y. Ju, and L. Li, "Criteria for strength and structural failure of rocks based on energy dissipation and energy release principles," Chinese Journal of Rock Mechanics and Engineering, vol. 24, no. 17, pp. 3003-3010, 2005.

[36] J. Kong, W. Jiang, and N. Chen, "Numerical analysis of roadway rock-burst hazard under superposed dynamic and static loads," Energies, vol. 12, no. 19, 2019.

[37] S. J. Gibowicz and A. Kijko, An Introduction to Mining Seismology, Earthquake Publish House, Carbondale, IL, USA, 1998.

[38] H. He, L. Dou, S. Gong, P. Zhou, and Z. Xue, "Rock burst rules induced by cracking of overlying key stratum," Chinese Journal of Geotechnical Engineering, vol. 32, no. 8, pp. 1260-1265, 2010.

[39] J. Dubinski and G. Mutke, “Application of PPV method for the assessment of stability hazard of underground excavations subjected to rock mass temors," AGH Journal of Mining and Geoengineering, vol. 36, pp. 125-132, 2012.

[40] A. Nierobisz, "Identification of load to dog heading support during a rockburst," Journal of Mining Science, vol. 52, no. 6, pp. 1129-1142, 2017.

[41] J. Qiao, N. Ma, J. Ma, Z. Zhao, X. Guo, and H. Shi, “Conjugate shear fracture-seismic composite model based on structural 
stability of dynamic system," Journal of China Coal Society, vol. 44, pp. 1637-1646, 2019.

[42] J. Ma, Z. Zhao, H. Shi, X. Guo, J. Qiao, and N. Ma, "Sources of seismic energy based on butterfly failure theory," Journal of China Coal Society, vol. 44, pp. 1654-1665, 2019.

[43] J. Ma, N. Ma, Z. Zhao, X. Guo, H. Shi, and J. Qiao, "Mechanical mechanism and evolution of X-shaped conjugate shear fractures-seism," Journal of China Coal Society, vol. 44, pp. 1647-1653, 2019.

[44] L. Jiang, P. Kong, P. Zhang et al., "Dynamic analysis of the rock burst potential of a longwall panel intersecting with a fault," Rock Mechanics and Rock Engineering, vol. 53, no. 4, pp. 1737-1754, 2019.

[45] C.-P. Lu, G.-J. Liu, N. Zhang, T.-B. Zhao, and Y. Liu, "Inversion of stress field evolution consisting of static and dynamic stresses by microseismic velocity tomography," International Journal of Rock Mechanics and Mining Sciences, vol. 87, pp. 8-22, 2016.

[46] J. Dubinski and G. Mutke, "Characteristics of mining tremors within the near-wave field zone," Pageoph, vol. 147, pp. 250-261, 1996.

[47] E. Aker, D. Kühn, V. Vavryčuk, M. Soldal, and V. Oye, "Experimental investigation of acoustic emissions and their moment tensors in rock during failure," International Journal of Rock Mechanics and Mining Sciences, vol. 70, pp. 286-295, 2014. 